\title{
SIMULATION AND ASSESSMENT OF AIR IMPINGEMENT COOLING ON SQUARED PIN-FIN HEAT SINKS APPLIED IN PERSONAL COMPUTERS
}

\author{
Hwa-Chong Tien \\ Associate Professor, Department of Mechanical and Mechatronic Engineering, National Taiwan Ocean University, \\ Keelung, Taiwan 202, ROC \\ Wei-Dong Huang \\ Graduate student, Department of Mechanical and Mechatronic Engineering, National Taiwan Ocean University, \\ Keelung, Taiwan 202, ROC, hctien@mail.ntou.edu.tw
}

Follow this and additional works at: https://jmstt.ntou.edu.tw/journal

Part of the Mechanical Engineering Commons

\section{Recommended Citation}

Tien, Hwa-Chong and Huang, Wei-Dong (2005) "SIMULATION AND ASSESSMENT OF AIR IMPINGEMENT COOLING ON SQUARED PIN-FIN HEAT SINKS APPLIED IN PERSONAL COMPUTERS," Journal of Marine Science and Technology: Vol. 13: Iss. 1, Article 3.

DOI: $10.51400 / 2709-6998.2100$

Available at: https://jmstt.ntou.edu.tw/journal/vol13/iss1/3

This Research Article is brought to you for free and open access by Journal of Marine Science and Technology. It has been accepted for inclusion in Journal of Marine Science and Technology by an authorized editor of Journal of Marine Science and Technology. 


\title{
SIMULATION AND ASSESSMENT OF AIR IMPINGEMENT COOLING ON SQUARED PIN-FIN HEAT SINKS APPLIED IN PERSONAL COMPUTERS
}

\author{
Hwa-Chong Tien* and Wei-Dong Huang**
}

Key words: jet impingement, pin-fin heat sinks, electronic cooling.

\begin{abstract}
The feasibility and effectiveness of air impingement cooling on pin-fin heat sinks applied in personal computers (PC) were investigated numerically in this study. The effects of fin height, fin width, base plate thickness of the heat sink, and ratio of the vertical spacing between the nozzle and the heat sink to jet diameter (z/D) were discussed in detail. For a PC with a P4, 2.8 GHz, 68.4 W CPU, it was found that the cooling effect by using air impingement on a heat sink with $z / D=4$ and fin width $4.13 \mathrm{~mm}$ for the jet Reynolds number $(R e)$ between 20000 to 25000 is comparable with the cooling effect achieved by using traditional coolers. When the fin width was increased to 5.3 $\mathrm{mm}$, the performance by jet impingement was improved significantly. Specifically, the cooling performance by jet impingement for $\mathrm{Re}=$ 15000 and fin width $5.3 \mathrm{~mm}$ surpasses that by using fan-heat sink coolers. Moreover, by changing the design of the PC chassis, we were able to increase the fin height and $z / D$ from $32.75 \mathrm{~mm}$ to $38.05 \mathrm{~mm}$ and from 4 to 8 , respectively. It was found that the cooling effect was further enhanced. When handling CPU's with higher power (> $80 \mathrm{~W})$, jet impingement cooling along with proper heat sink design and PC chassis design offers another possible choice.
\end{abstract}

\section{INTRODUCTION}

The demand for system performance of personal computers and notebook computers has increased tremendously in recent years. The power consumption thus increases accordingly. Moreover, due to the trend of miniaturization, the power density of the CPU's has reached incredibly high level. Renovated cooling technology seems to be a must in the near future.

There are a number of aggressive cooling approaches under development. Air jet impingement (JI)

Paper Submitted 08/06/04, Accepted 10/06/04. Author for Correspondence: Hwa-Chong Tien.E-mail: hctien@mail.ntou.edu.tw.

*Associate Professor, Department of Mechanical and Mechatronic Engineering, National Taiwan Ocean University, Keelung, Taiwan 202, ROC.

**Graduate student, Department of Mechanical and Mechatronic Engineering, National Taiwan Ocean University, Keelung, Taiwan 202, ROC. associated with surface enhancement such as heat sinks has received extensive attention. JI can usually result in high local heat transfer rate in the region of stagnation point. The heat-removal level due to JI along with a heat sink is comparable with liquid cooling. Detailed review on JI can be found in Downs and James [1], and Jambunathan et al. [3]. Several key findings are addressed here.

Considering a circular jet impinging on a heated plate, the heat transfer coefficient was shown to have a bell-shaped distribution. The maximum appears at the stagnation point, and the value of the heat transfer coefficient decays outwards. It was found that a second peak for the heat transfer coefficient appears under the condition of $z / D<6$, where $z / / D$ denotes the ratio of jet height to the jet diameter. It was also found that the confinement on the flow has the effect of reducing the Nusselt number. However, such effect diminishes as the jet diameter increases.

Guarino and Manno [2] discussed cooling of JI applied in the CPU of a notebook computer for low Reynolds number, Re $<1500$ (laminar flow). The cooling effect of increasing the jet velocity was found to be much stronger than increasing the jet diameter. The power consumption for the JI is less than that for the fan used in the original computer under the condition of similar cooling effect. Maveety and Jung $[4,7,8]$ investigated the air impingement cooling on the squared pin-fin heat sink under turbulent conditions. It was found that among various pin fin sizes (say, $5 \times 5$ to 13 $\times 13)$ an optimal size for the pin fin array exists, which is $7 \times 7$. An increase in the fin height can enhance the cooling effect, that is, the total thermal resistance is reduced. However, beyond a certain value for the fin height $(15 \mathrm{~mm})$, the decrease in the thermal resistance is insignificant. It is noted that the above results are based on $z / D=10$.

This paper numerically investigates air impingement cooling on a squared aluminum pin-fin heat sink, 
which is installed in a desktop personal computer, as shown in Figure 1. Attention is first given to the performance of the squared pin-fin heat sink subjected to JI. Several effects are studied. Then a selected cooling configuration is placed in a PC to evaluate overall cooling performance, and a comparison is also made between JI and a traditional cooling system with fan and heat sink combination. The main contribution of present work is to numerically explore the feasibility of using JI on a heat sink in a PC from the view point of heat transfer. To the best of the authors' knowledge, none of the studies in the literature performed such analysis, except [2]. It dealt with low speed (laminar) JI cooling in notebook computers, which consume relatively lower power (less than $30 \mathrm{~W}$ ).

\section{MATHEMATICAL FORMULATION}

In this study, a number of assumptions and simplifications are made to analyze the thermal and fluid fields. These include: (a) steady state, (b) incompressible flow, (c) constant properties, (d) neglecting viscous dissipation in the energy equation, and (e) neglecting buoyancy effects. Based on the afore-mentioned assumptions, the three-dimensional time-averaged continuity, Navier-Stokes and energy equations are written as follows.

$$
\begin{aligned}
& \frac{\partial\left(\rho u_{j}\right)}{\partial x_{j}}=0 \\
& \frac{\partial\left(\rho u_{j} u_{i}\right)}{\partial x_{j}}=-\frac{\partial p}{\partial x_{i}}+\frac{\partial}{\partial x_{j}}\left[\mu_{e f f}\left(\frac{\partial u_{i}}{\partial x_{j}}+\frac{\partial u_{j}}{\partial x_{i}}\right)\right] \\
& \frac{\partial\left(\rho u_{j} H\right)}{\partial x_{i}}=\frac{\partial}{\partial x_{j}}\left(\Gamma_{e f f} \frac{\partial H}{\partial x_{j}}\right)
\end{aligned}
$$

where the effective viscosity $\mu_{e f f}$ and the effective thermal diffusivity $\Gamma_{\text {eff }}$ are defined as

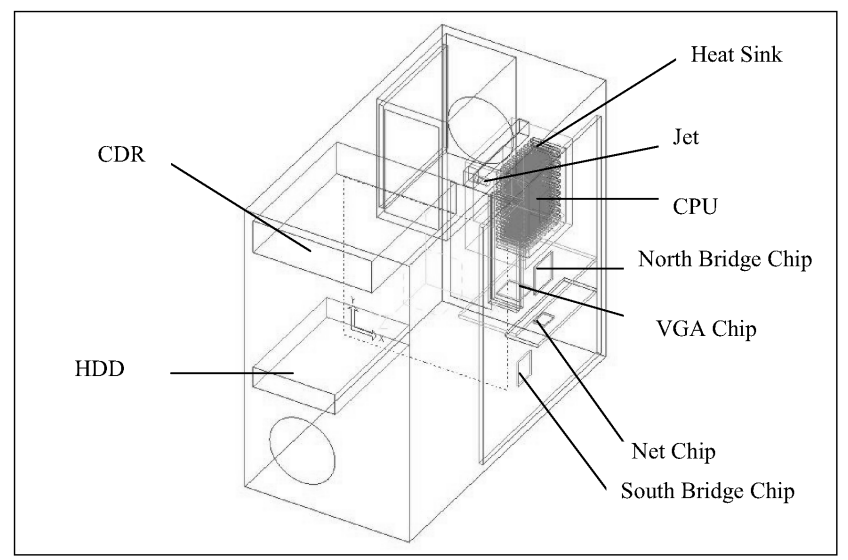

Fig. 1. Schematic diagram of the PC chassis.

$$
\mu_{e f f}=\mu+\mu_{t}
$$

and

$$
\Gamma_{\text {eff }}=\frac{\mu}{\operatorname{Pr}}+\frac{\mu_{t}}{\operatorname{Pr}_{t}}
$$

In equations (4) and (5), $\mu$ and Pr denote the dynamic viscosity and the Prandtl number of the fluid while $\mu_{t}$ and $\operatorname{Pr}_{t}$ denote the turbulent viscosity and turbulent Prandtl number for the turbulent flows, respectively.

\section{METHOD OF SOLUTION}

Due to the complexity of the present problem, it is impractical and quite time consuming to develop user's own numerical code. Therefore, one of widely used commercial codes IDEAS-ESC is adopted for analyzing the pertinent problem. The detail of the current numerical scheme is described in [9]. It is noted that two turbulence models are available in IDEAS-ESC, which are fixed viscosity model and two-equation $k-\varepsilon$ model. The two-equation $k-\varepsilon$ model is chosen in this study for its accuracy; despite the fact that the computational time increases tremendously. The general convergence criterion after testing is chosen as $2 \times 10^{-4}$ for the root mean square residuals of mass, momentum in the $x, y$, and $z$ directions, and energy.

Thermal resistance is an important quantity to characterize the performance of a heat sink. It is defined by the following equation

$$
\theta_{j a}=\frac{T_{j}-T_{a}}{Q}
$$

where $T_{j}, T_{a}$, and $Q$ denote the center temperature of the CPU surface, air temperature at the nozzle exit, and the power generated by the CPU, respectively.

\section{RESULTS AND DISCUSSION}

As mentioned earlier, this work first conducts a parametric study on the effects of jet Reynolds numbers, number of arrays, vertical spacing between the nozzle and the heat sink, width and length of fins, and thickness of the base plate of the heat sink. Next, a chosen heat sink with a suitable spacing is installed in a personal computer to evaluate the thermal performance under various operating conditions.

\section{Accuracy of the present numerical scheme}

Before we discuss the miscellaneous results, it is essential to examine the accuracy of the numerical scheme used in the work. The effect of the mesh size is 
investigated by selecting a representative case, which is a heat sink with $7 \times 7$ squared fins for $z / D=10, \mathrm{Re}=$ 15520. The jet Reynolds number is defined as $\mathrm{Re}=V D /$ $v_{a}$, where $V$ and $D$ denote, respectively, the velocity and diameter of the jet, and $v_{a}$ is the kinematic viscosity of air. Figure 2 illustrates the results of the thermal resistance of the heat sink based on different grids. It can be seen clearly that the thermal resistance is almost unchanged within the range of grids from 129452 to 187554. Therefore in order to achieve both acceptable accuracy for the results and saving in computational time, the subsequent calculations for JI on a heat sink are based on the grids of $1.3 \times 10^{5}$ approximately. It was found that the computational time for such a typical case by using a Pentum $4,1.5 \mathrm{GHz}$ PC is approximately 5 hours. It should be mentioned that for different numbers of fins considered in this work, the mesh size employed differs somewhat from each other. Another check is made by comparing the present results for JI on a heat sink with previous studies. Figure 3 shows that the present results are in good agreement with previous computational and experimental results [8]. It should be mentioned that the numerical results of [8] are also based on the $k-\varepsilon$ turbulence model. However, it is somewhat difficult to explain the minor disagreement between the current work and [8], since a different commercial code FLOTHERM was used in [8]. In addition, the slight difference between the present results and the experimental results of [8] might be due to the uncertainty in the experimental work of [8].

\section{Effects of controlling parameters on the thermal resis- tance}

The jet simulated in this work is assumed to be a circular jet of uniform flow. The diameter of the jet is fixed as $8 \mathrm{~mm}$. The specifications of the heat sink considered in this study are listed in Table 1, which is based on the work of Ledezma et al. [5]. Figure 4 depicts the variation of the total thermal resistance of the heat sink vs. size of the heat sinks subjected to different jet Reynolds numbers. It can be seen clearly that the thermal resistance decreases as $R e$ increases due to the enhancement of cooling. However, such an increase in cooling with increasing $R e$ diminishes gradually. Figure 4 also indicates that the heat sink of $10 \times 13$ fins displays the lowest thermal resistance for all the jet Reynolds numbers considered in this work. The reason for such phenomena can be explained as follows. When the number of the fins increases beyond

Table 1. The specifications of the heat sink considered in this study

\begin{tabular}{cccccccc}
\hline $\begin{array}{c}\text { Fin array } \\
\mathrm{Nx} \times \mathrm{Ny}\end{array}$ & Fin number & $\begin{array}{c}D_{f} \\
(\mathrm{~mm})\end{array}$ & $\begin{array}{c}s \\
(\mathrm{~mm})\end{array}$ & $\begin{array}{c}s^{*} \\
(\mathrm{~mm})\end{array}$ & $\begin{array}{c}A_{f} \\
\left(\mathrm{~cm}^{2}\right)\end{array}$ & $\begin{array}{c}A_{t} \\
\left(\mathrm{~cm}^{2}\right)\end{array}$ & $\begin{array}{c}\text { Volume } \\
\left(\mathrm{cm}^{3}\right)\end{array}$ \\
\hline $8 \times 10$ & 80 & 6.14 & 3.70 & 3.733 & 8.04 & 714.72 & 148.65 \\
$9 \times 11$ & 99 & 5.00 & 3.75 & 4.000 & 6.55 & 719.70 & 130.93 \\
$10 \times 12$ & 120 & 4.13 & 3.74 & 4.131 & 5.41 & 720.49 & 116.91 \\
$10 \times 13$ & 130 & 4.13 & 3.74 & 3.443 & 5.41 & 774.59 & 122.49 \\
$11 \times 14$ & 154 & 3.45 & 3.71 & 3.592 & 4.52 & 767.25 & 109.91 \\
$12 \times 15$ & 180 & 2.86 & 3.70 & 3.721 & 3.75 & 745.64 & 98.09 \\
$13 \times 16$ & 208 & 2.35 & 3.70 & 3.827 & 3.08 & 711.58 & 87.49 \\
\hline
\end{tabular}

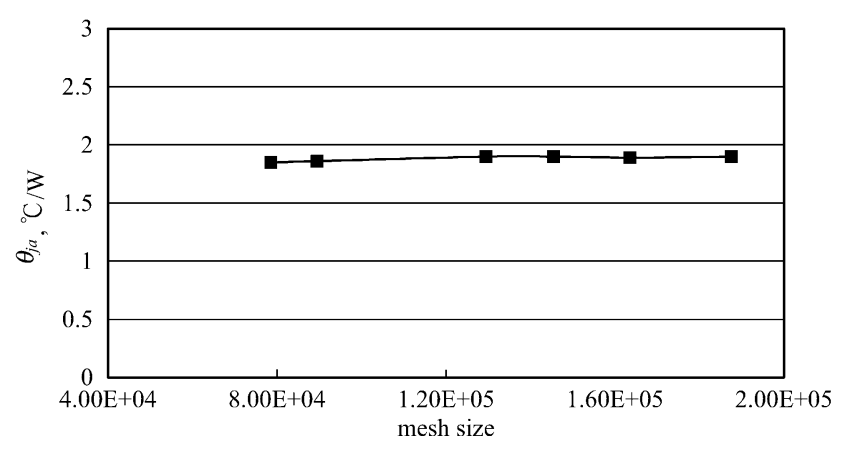

Fig. 2. Thermal resistance of the heat sink based on various grids for $z / D=10$ and $\operatorname{Re}=15520$.

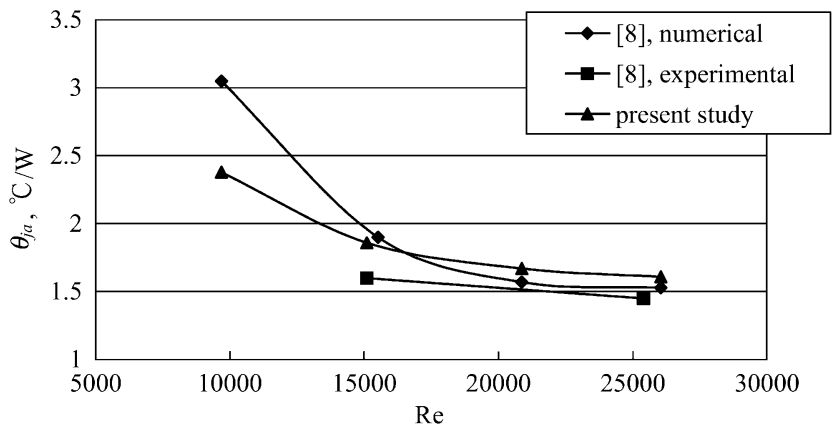

Fig. 3. Comparison between the present study and previous results, with $7 \times 7$ fins and $z / D=10$. 
an optimal value, it can result in a decrease for the width of flow channel and hence a larger pressure drop. This yields shallow penetration for the jet into the space between fins, and causes insufficient cooling and hence a higher thermal resistance. Nevertheless, when the fin number decreases below the optimum, it can reduce the turbulence intensity of the flow flowing in the heat sink. The heat transfer rate is thus decreased and the thermal resistance is increased. It is noted that the 'optimum' for a controlling parameter such as the number of fin arrays and $z / D$ is defined as the value under which the thermal resistance of the heat sink arrives at the minimum.

Based on $10 \times 13$ fins, $\mathrm{Re}=15000$, fin width= $4.13 \mathrm{~mm}$, the effect of the fin height is shown in Figure 5. It indicates that increasing the fin height can decrease the thermal resistance; however, such a decrease in the thermal resistance tends to die down. This is because increasing the fin height can increase the heat transfer area whereas it is more difficult for the flow to penetrate into the inside surface of the heat sink. The effect of the fin width is shown in Figure 6 for $10 \times 13$ fins, $R e=15000$, fin height $=32.75 \mathrm{~mm}$. Apparently, an increase in the fin width can cause a decrease in the thermal resistance. A minimum for the thermal resistance appears. This is due to the fact that when the fin width increases such that the fluid channel reduces below the optimum, the

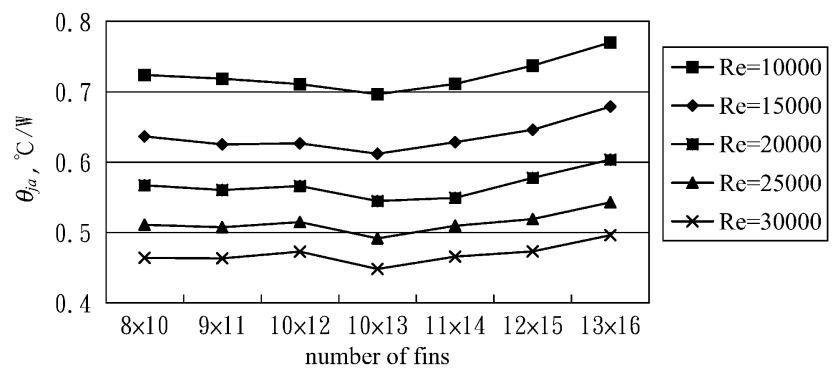

Fig. 4. Thermal resistance versus number of fins for $z / D=8$ at various Reynolds numbers.

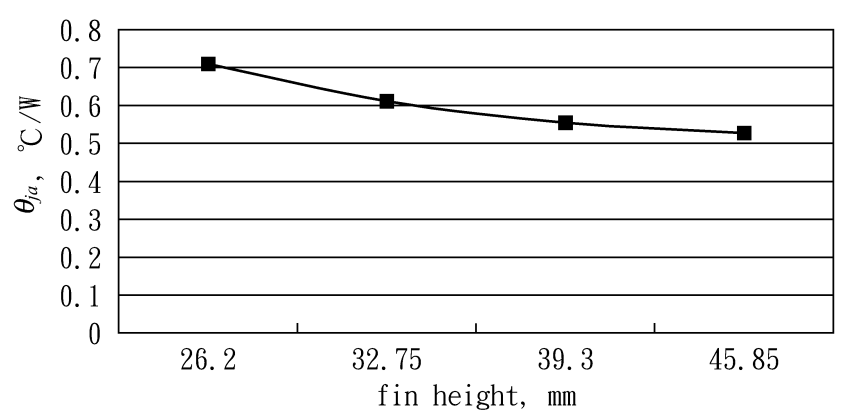

Fig. 5. The dependence of thermal resistance on the fin height for 10 $\times 13$ fins, $z / D=8, \operatorname{Re}=15000$, and fin width $=4.13 \mathrm{~mm}$ jet cannot penetrate into the space between fins freely. It is worthwhile to examine the effect of the thickness of the base plate of the heat sink. From Figure 7, it can be seen that an increase in the thickness of the base plate causes a decrease in the thermal resistance; however, the trend is getting less pronounced as the thickness of the base plate keeps increasing. This attributes to the fact that increasing the thickness of the base plate can decrease the lateral thermal resistance due to the increase in the lateral heat transfer area. Nevertheless, the thermal resistance in the vertical direction increases accordingly. Finally, the effect of $z / D$ is examined based on the heat sink with $10 \times 13$ fins for $\operatorname{Re}=15000$, fin height $=32.75 \mathrm{~mm}$, fin width $=5.3 \mathrm{~mm}$ as displayed in Figure 8. It is interesting to learn that the case of $z / D=$ 8 yields lower thermal resistance than the other cases. This is because a suitable space between the jet and the heat sink, $z / D$, will generate better overall cooling effect. It was found that for moderate Reynolds numbers such as $\operatorname{Re}=15000$, the optimal value for $z / D$ is close to 8 .

The above results are qualitatively similar to

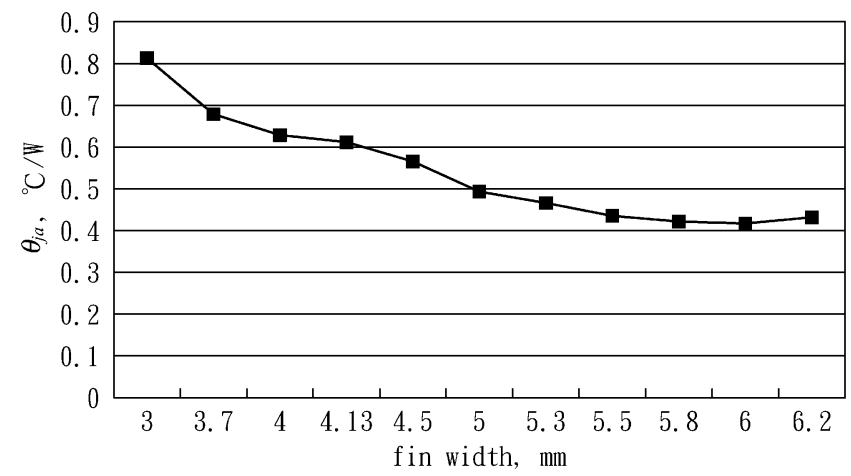

Fig. 6. The dependence of thermal resistance on the fin width for $10 \times$ 13 fins, $z / D=8, \operatorname{Re}=15000$, and fin height $=32.75 \mathrm{~mm}$.

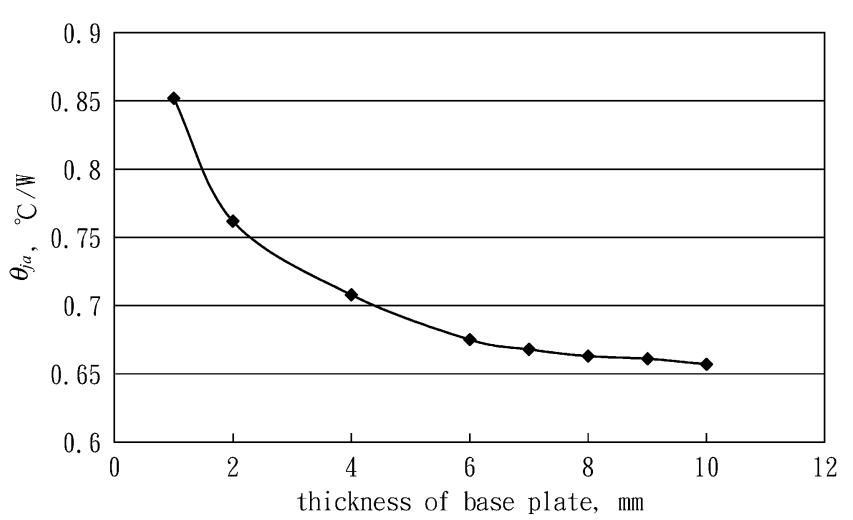

Fig. 7. The dependence of thermal resistance on the thickness of base plate for $10 \times 13$ fins, $z / D=8, R e=15000$, fin height $=32.75 \mathrm{~mm}$, and fin width $=4.13 \mathrm{~mm}$. 
Maveety and Jung [4, 7, 8]. However, it should be mentioned that the main objective of the present study is to investigate the cooling effect when implementing the jet and the heat sink in the personal computers, which is now discussed below.

\section{Results of JI cooling on the heat sink installed in a personal computer}

After discussing the effects of the pertinent controlling parameters of the jet and the heat sink, it is suitable to present the results of JI on a heat sink installed in a personal computer. The case simulated is based on a PC equipped with an Intel P4, $2.8 \mathrm{GHz}$, $68.4 \mathrm{~W}$ or $3.06 \mathrm{GHz}, 80-81.8 \mathrm{~W}$ processor. The key components are shown in Figure 1, where the original CPU cooler (a fan and a heat sink) is replaced by a nozzle and a heat sink. Now, there are two fans left in the PC; one is at the front cover to induce the fresh cooling air and the other is at the rear side of the power supply to exhaust the heated air. The simulated result for this PC will be compared with a previous study based on the original configurations [6]. The jet diameter is set as 8 $\mathrm{mm}$, and $z / D$ is chosen as 4 due to limited space in the CPU. The jet temperature is set as $35^{\circ} \mathrm{C}$, which is the same as the ambient temperature. The dimensions for the heat sink with $10 \times 13$ fins are specified as follows: Base plate thickness and fin height are $7 \mathrm{~mm}$ and 32.75

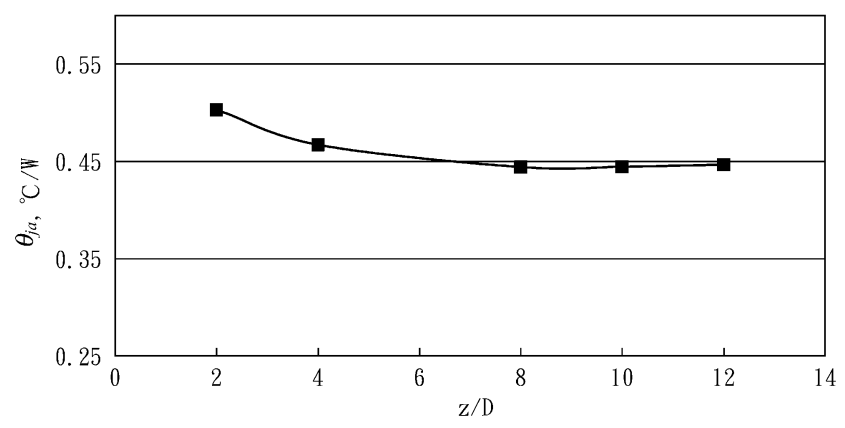

Fig. 8. Thermal resistance versus $z / D$ for $10 \times 13$ fins, $z / D=8, \mathrm{Re}=$ 15000 , fin height $=32.75 \mathrm{~mm}$, and fin width $=5.3 \mathrm{~mm}$. $\mathrm{mm}$, respectively. In addition, fin widths of $4.13 \mathrm{~mm}$ and $5.3 \mathrm{~mm}$ are used.

Table 2 lists the results of the temperature for various components in the $\mathrm{PC}$ with a $\mathrm{P} 4,2.8 \mathrm{GHz}, 68.4$ $\mathrm{W}$ processor. The fin width of the heat sink is $4.13 \mathrm{~mm}$. It can be seen clearly that as the Reynolds number increases from 15000 to 30000 , the temperature of the $\mathrm{CPU}$ and the heat sink drops down accordingly. However the temperature of the other components essentially stays unchanged. This is due to the fact that the air jet impinges on the heat sink and hence has a direct impact on the CPU temperature. The rest components in the PC are only influenced indirectly. It is interesting to compare the cooling effect by using air impingement with that by using traditional coolers. Therefore, a commercially available PC is considered. This PC was originally equipped with a $\mathrm{P} 4,1.5 \mathrm{GHz}, 54.7 \mathrm{~W}$ processor cooled by a traditional fan-heat sink cooler, which was studied in [6]. It should be mentioned that in [6] the fan was quite close to the heat sink and the heat sink is a common commercial one, which is different from the squared pin-fin heat sink considered in the present work. For the purpose of direct comparison, the P4, $1.5 \mathrm{GHz}, 54.7 \mathrm{~W}$ CPU is now replaced by a $2.8 \mathrm{GHz}$, $68.4 \mathrm{~W}$ processor. It can be seen from Table 2 that the cooling effect by using air impingement for the Reynolds number between 20000 and 25000 is comparable with the cooling effect achieved by using traditional coolers.

To improve the cooling effect by using air impingement along with a heat sink, the width of the fin is increased from $4.13 \mathrm{~mm}$ to $5.3 \mathrm{~mm}$. As we discussed before, the performance of the heat sink could be enhanced by increasing the fin width. Table 3 indicates the temperatures for the key components inside the PC. It is noted that for $\operatorname{Re}=15000$, the temperature of the CPU reads $65.37^{\circ} \mathrm{C}$, lower than $69.8^{\circ} \mathrm{C}$ in [6] as shown in Table 2, and also lower than $75^{\circ} \mathrm{C}$ the specification suggested by Intel. It is also interesting to examine the flow and thermal fields. Figures 9 and 10 display the flow and thermal fields at X-Y section for $\mathrm{Re}=15000$, respectively. Figures 9 and 10 indicate that the region of the heat sink influenced by the jet impingement is not broad due to the fact that the ratio of jet height to the jet

Table 2. Temperatures for the key components in the PC cooled by air impingement, and by traditional coolers (fan and heat sink) [6]. The CPU power is $68.4 \mathrm{~W}$, and the fin width and the fin height of the heat sink are $4.13 \mathrm{~mm}$, and $32.75 \mathrm{~mm}$, respectively

\begin{tabular}{cccccccccc}
\hline & $\mathrm{T}_{\mathrm{CPU}}$ & $\mathrm{T}_{\text {North }}$ & $\mathrm{T}_{\text {South }}$ & $\mathrm{T}_{\mathrm{VGA}}$ & $\mathrm{T}_{\text {Net }}$ & $\mathrm{T}_{\mathrm{M} 1}$ & $\mathrm{~T}_{\mathrm{HS}}$ & $\mathrm{T}_{\mathrm{HDD}}$ & $\mathrm{T}_{\mathrm{CDR}}$ \\
\hline $\mathrm{Re}=15000$ & 75.40 & 82.28 & 45.87 & 84.12 & 43.81 & 53.71 & 69.42 & 42.86 & 41.26 \\
$\mathrm{Re}=20000$ & 70.96 & 81.72 & 45.87 & 84.17 & 43.81 & 52.53 & 65.05 & 42.78 & 40.69 \\
$\mathrm{Re}=25000$ & 67.56 & 81.21 & 45.86 & 84.33 & 43.81 & 51.51 & 61.68 & 42.51 & 40.35 \\
$\mathrm{Re}=30000$ & 64.86 & 80.68 & 45.83 & 84.58 & 43.83 & 50.58 & 59.01 & 42.18 & 40.03 \\
Lin [6] & 69.80 & 79.26 & 43.95 & 81.92 & 44.51 & 54.81 & 49.25 & 42.38 & 42.65 \\
\hline
\end{tabular}


diameter $z / D$ is not large enough. Although the cooling effect for the CPU with $68.4 \mathrm{~W}$ under air impingement seems to be satisfactory, such arrangement is not capable of handling CPU's with more power. Table 4 indicates the temperatures for the components when the CPU power increases to $80 \mathrm{~W}$ with fin width of $5.3 \mathrm{~mm}$. It can be seen that the cooling effect for this case is not sufficient unless Re goes beyond 25000. We are aware that the number of fins used in this study is not at optimum. Following the procedure described in Maveety and Jung $[4,7,8]$, the optimal values for the fin height for various fin widths and Reynolds numbers are displayed in Figure 11. It can be seen that the fin height used so far, which is $32.75 \mathrm{~mm}$, is below the optimal values for most cases. Therefore we are motivated to alter the present design for the PC chassis.

Figures 12 and 13, respectively, indicate the thermal and flow fields for $z / D=8$, fin height $=38.05 \mathrm{~mm}$, and CPU power $=80 \mathrm{~W}$. We are allowed to increase both values for $z / D$ and the fin height because we increase the height of the chassis about $2 \mathrm{~cm}$ and rotate the power supply by 90 degrees. It can be seen from Figures 12 and 13 that the region of the heat sink influenced by the jet impingement is broader than that in Figures 9 and 10. This effect plus the increase in the fin height renders better cooling, shown in Table 5, as compared with Tables 3 and 4 . Therefore using jet impingement cooling along with suitable heat sink design and PC chassis design demonstrates the possibility of handling high power CPU's.

\section{CONCLUSION}

This paper first investigates cooling effects of air jet impingement on a squared pin-fin heat sink. Then a heat sink of the optimal size $10 \times 13$ along with the jet is placed in a PC to evaluate overall thermal performance, and a comparison is made between $\mathrm{JI}$ and traditional cooling system with fan and heat-sink combination. The results obtained in this work can be concluded as

Table 3. Temperatures for the key components in the PC cooled by air impingement. The CPU power is $68.4 \mathrm{~W}$ and the fin width, and the fin height of the heat sink are $5.3 \mathrm{~mm}$ and $32.75 \mathrm{~mm}$, respectively

\begin{tabular}{cccccccccc}
\hline & $\mathrm{T}_{\mathrm{CPU}}$ & $\mathrm{T}_{\text {North }}$ & $\mathrm{T}_{\text {South }}$ & $\mathrm{T}_{\mathrm{VGA}}$ & $\mathrm{T}_{\text {Net }}$ & $\mathrm{T}_{\mathrm{M} 1}$ & $\mathrm{~T}_{\mathrm{HS}}$ & $\mathrm{T}_{\mathrm{HDD}}$ & $\mathrm{T}_{\mathrm{CDR}}$ \\
\hline $\mathrm{Re}=15000$ & 65.37 & 82.10 & 45.57 & 80.48 & 43.31 & 54.73 & 58.92 & 42.34 & 39.85 \\
$\mathrm{Re}=20000$ & 62.98 & 81.82 & 45.57 & 80.58 & 43.28 & 53.98 & 56.24 & 42.33 & 39.72 \\
$\mathrm{Re}=25000$ & 61.25 & 81.35 & 45.56 & 80.60 & 43.23 & 52.68 & 54.46 & 42.38 & 39.61 \\
\hline
\end{tabular}

Table 4. Temperatures for the key components in the PC cooled by air impingement. The CPU power is $80 \mathrm{~W}$, and the fin width, and the fin height of the heat sink are $5.3 \mathrm{~mm}$ and $32.75 \mathrm{~mm}$, respectively

\begin{tabular}{cccccccccc}
\hline & $\mathrm{T}_{\mathrm{CPU}}$ & $\mathrm{T}_{\text {North }}$ & $\mathrm{T}_{\text {South }}$ & $\mathrm{T}_{\mathrm{VGA}}$ & $\mathrm{T}_{\mathrm{Net}}$ & $\mathrm{T}_{\mathrm{M} 1}$ & $\mathrm{~T}_{\mathrm{HS}}$ & $\mathrm{T}_{\mathrm{HDD}}$ & $\mathrm{T}_{\mathrm{CDR}}$ \\
\hline $\mathrm{Re}=25000$ & 66.26 & 81.87 & 44.66 & 80.76 & 43.32 & 53.95 & 58.15 & 42.89 & 40.21 \\
$\mathrm{Re}=30000$ & 64.50 & 81.53 & 44.67 & 80.90 & 43.31 & 53.73 & 56.57 & 42.65 & 39.92 \\
\hline
\end{tabular}

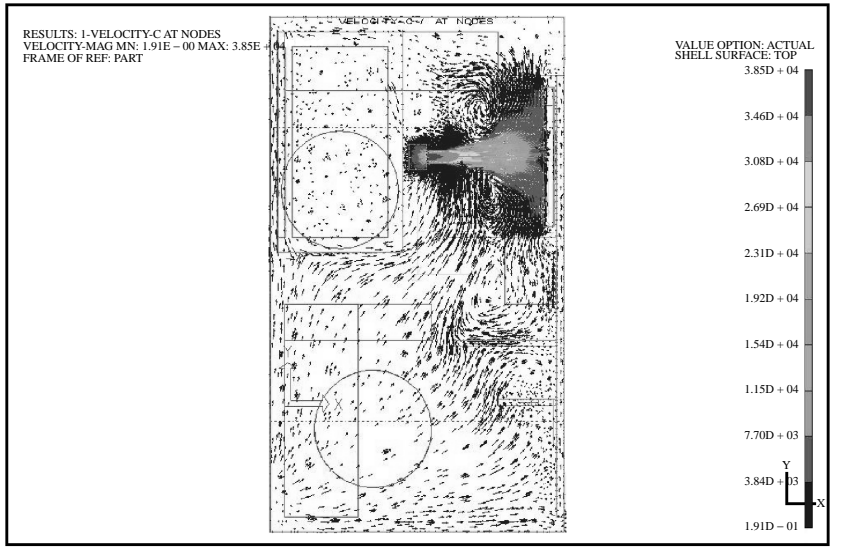

Fig. 9. Air flow field in $x-y$ plane for $\operatorname{Re}=15000$.

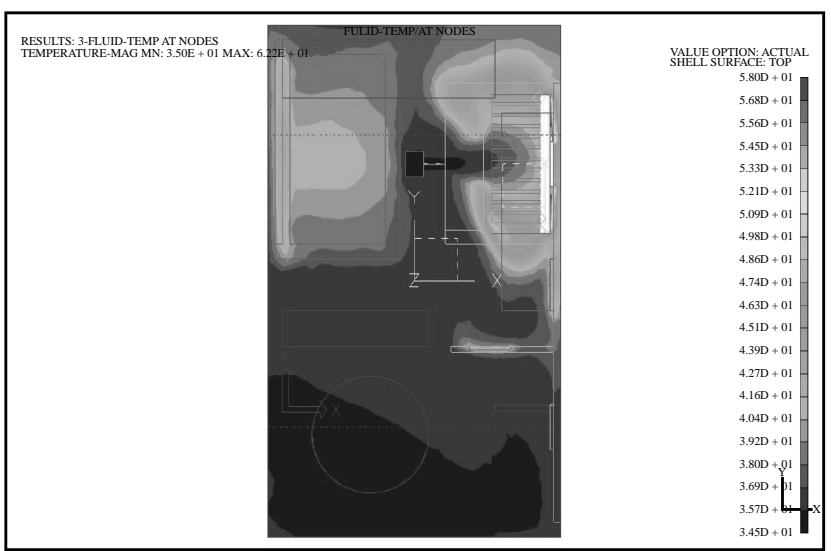

Fig. 10. Thermal field of air in $x-y$ plane for $\operatorname{Re}=15000$. 
Table 5. Temperatures for the key components in the PC cooled by air impingement. The CPU power is $68.4 \mathrm{~W}, 80 \mathrm{~W}$ or $81.8 \mathrm{~W}$, and the fin width and the fin height of the heat sink are $5.3 \mathrm{~mm}$ and $38.05 \mathrm{~mm}$, respectively

\begin{tabular}{lccccccccc}
\hline & $\mathrm{T}_{\mathrm{CPU}}$ & $\mathrm{T}_{\text {North }}$ & $\mathrm{T}_{\text {South }}$ & $\mathrm{T}_{\mathrm{VGA}}$ & $\mathrm{T}_{\mathrm{Net}}$ & $\mathrm{T}_{\mathrm{M} 1}$ & $\mathrm{~T}_{\mathrm{HS}}$ & $\mathrm{T}_{\mathrm{HDD}}$ & $\mathrm{T}_{\mathrm{CDR}}$ \\
\hline $\mathrm{Re}=20000(68.4 \mathrm{~W})$ & 61.18 & 81.75 & 43.86 & 79.54 & 44.14 & 49.51 & 53.52 & 42.11 & 38.77 \\
$\mathrm{Re}=20000(80 \mathrm{~W})$ & 64.91 & 82.37 & 44.06 & 80.00 & 44.40 & 50.13 & 55.72 & 42.16 & 38.91 \\
$\mathrm{Re}=25000(80 \mathrm{~W})$ & 63.81 & 82.05 & 44.15 & 80.12 & 44.42 & 49.95 & 54.87 & 42.25 & 38.90 \\
$\mathrm{Re}=30000(80 \mathrm{~W})$ & 62.92 & 81.85 & 44.21 & 80.25 & 44.48 & 49.82 & 54.01 & 42.39 & 38.87 \\
$\mathrm{Re}=30000(81.8 \mathrm{~W})$ & 63.55 & 81.92 & 44.23 & 80.32 & 44.50 & 49.90 & 54.02 & 42.38 & 38.88 \\
\hline
\end{tabular}

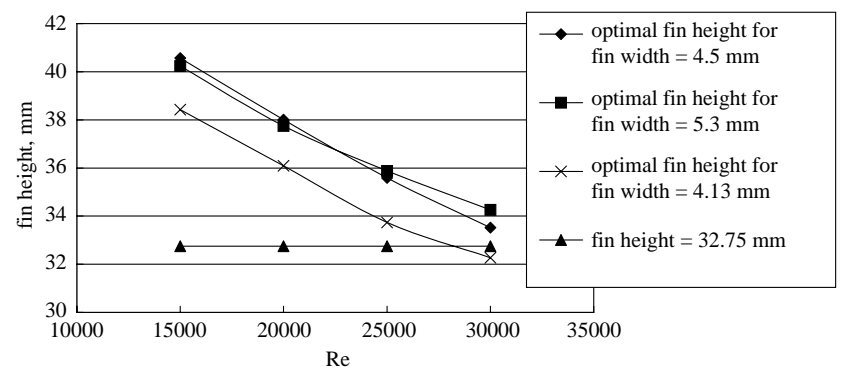

Fig. 11. Optimal fin height for several fin widths at various Reynolds numbers.

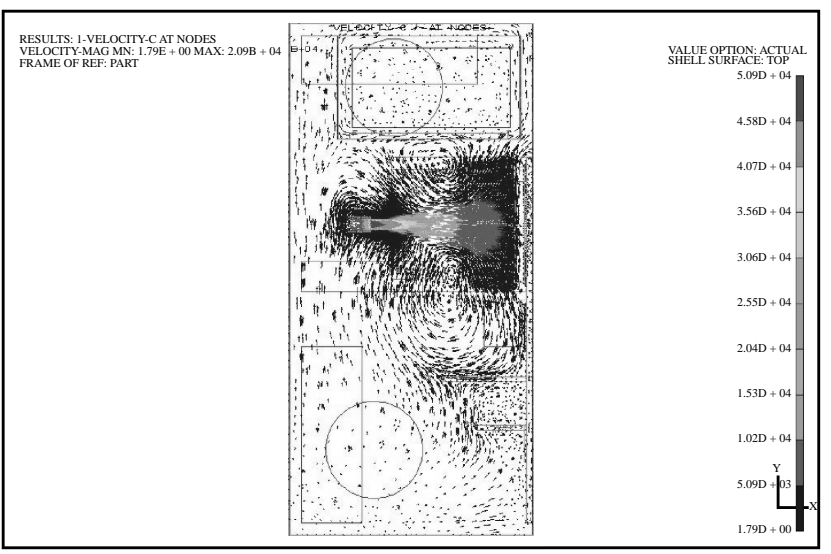

Fig. 12. Air flow field in $x-y$ plane for $\operatorname{Re}=\mathbf{2 5 0 0 0}$, after improvements.

follows.

1. The increase in the jet velocity and the thickness of the base plate causes a decrease in the thermal resistance of the heat sink. However, the trend slows down as these two parameters increase further.

2. An optimum was found for the fin width as well as the jet height, $z / D$. Under such circumstance, the thermal resistance arrives at its minimum.

3. An increase in the fin height can increase the heat transfer area and hence cause a decrease in the thermal resistance.

4. Regarding a commercial PC with a P4, 2.8 GHz, 68 .

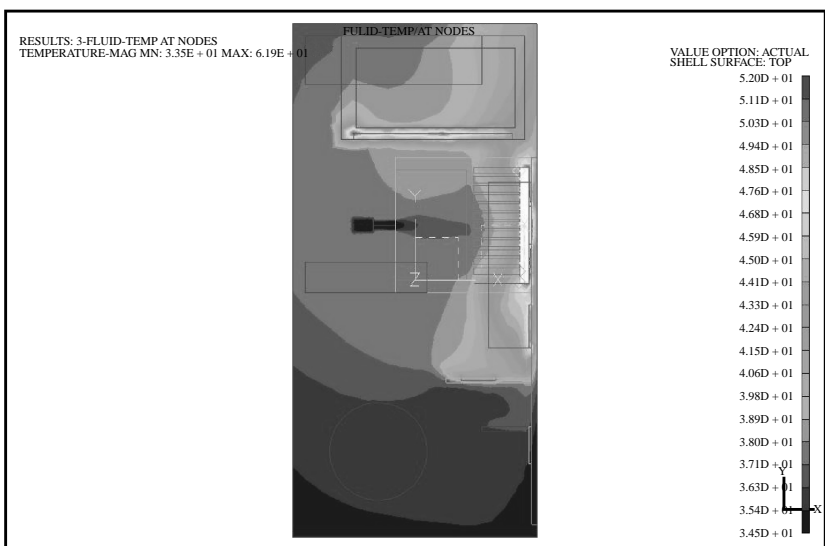

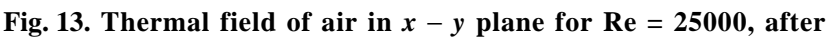
improvements.

$4 \mathrm{~W}$ CPU, the cooling effect by using air impingement on a heat sink with $z / D=4$ and fin width $4.13 \mathrm{~mm}$ for the Reynolds number between 20000 to 25000 is comparable with the cooling effect achieved by using traditional coolers.

5. Increasing the fin width to $5.3 \mathrm{~mm}$, the cooling performance by JI for $\mathrm{Re}=15000$ and fin width $=5.3 \mathrm{~mm}$ surpasses that by using traditional coolers.

6. By changing the design of the PC chassis, we were able to increase the fin height and the jet height, $z / D$, from $32.75 \mathrm{~mm}$ to $38.05 \mathrm{~mm}$ and from 4 to 8 , respectively. The cooling effect was found to be further enhanced. Using jet impingement cooling along with suitable heat sink design and PC chassis design demonstrates the possibility of handling high power CPU's(> $80 \mathrm{~W})$.

\section{NOMENCLATURE}

$A_{f} \quad$ surface area of a single fin $\left[\mathrm{cm}^{2}\right]$

$A_{t} \quad$ total surface area of a pin-fin heat sink $\left[\mathrm{cm}^{2}\right]$

$D \quad$ jet diameter $=8 \mathrm{~mm}$

$D_{f} \quad$ fin width [mm]

$H \quad$ static enthalpy $[\mathrm{kJ} / \mathrm{kg}]$

$N \quad$ number of fin array 


$\begin{array}{ll}p & \text { pressure [Pa] } \\ P r & \text { Prandtl number of air } \\ P r_{t} & \text { turbulent Prandtl number } \\ Q & \text { power generated by the CPU [W] } \\ s & \text { spacing in } x \text {-direction between two adjacent } \\ & \text { fins [mm] } \\ s^{*} & \text { spacing in } y \text {-direction between two adjacent } \\ & \text { fins [mm] } \\ T & \text { Temperature }\left[{ }^{\circ} \mathrm{C}\right] \\ T_{a} & \text { Temperature of the ambient }\left[{ }^{\circ} \mathrm{C}\right] \\ T_{j} & \text { Temperature of the center of the CPU }\left[{ }^{\circ} \mathrm{C}\right] \\ u_{i}, u_{j} & \text { velocity of air }[\mathrm{m} / \mathrm{s}] \\ x_{i} & \text { coordinates }[\mathrm{m}] \\ z & \text { height of the jet }[\mathrm{cm}]\end{array}$

\section{Greek Symbols}

$\begin{array}{ll}\mu & \text { dynamic viscosity of air }[\mathrm{kg} / \mathrm{m}-\mathrm{s}] \\ \mu_{t} & \text { turbulent dynamic viscosity of air }[\mathrm{kg} / \mathrm{m}-\mathrm{s}] \\ \theta_{j a} & \text { thermal resistance of the heat sink }\left[{ }^{\circ} \mathrm{C} / \mathrm{W}\right] \\ \rho & \text { density of air }\left[\mathrm{kg} / \mathrm{m}^{3}\right] \\ \Gamma_{\text {eff }} & \text { effective thermal diffusivity of air }[\mathrm{kg} / \mathrm{m}-\mathrm{s}]\end{array}$

\section{Subscripts}

$\begin{array}{ll}\text { HS } & \text { heat sink } \\ \text { M1 } & \text { memory chip } \\ \mathrm{x} & \text { in } x \text {-direction } \\ \mathrm{y} & \text { in } y \text {-direction }\end{array}$

\section{REFERENCES}

1. Downs, A. and James, M., "Jet Impingement Heat Trans-
fer-A Literature Survey," Proceedings of the National Heat Transfer Conference, No. 87-HT-35 (1987).

2. Guarino, R. and Manno, P., "Characterization of Laminar Jet Impingement Cooling in Portable Computer Applications," IEEE T. Compon. Pack. T., Vol.25, pp. 337-346 (2002).

3. Jambunathan, K., Lai, E., Moss, M.A., and Button, B.L., "A Review of Heat Transfer Data for Single Circular Jet Impingement," Int. J. Heat Fluid Flow, Vol. 13, pp. 106 -115 (1992).

4. Jung, H.H. and Maveety, J.G., "Pin-Fin Heat Sink Modeling and Characterization," $16^{\text {th }}$ IEEE SEMI-THERM Symposium (2000).

5. Ledezma, G., Morega, A.M., and Bejan, A., "Optimal Spacing Between Pin Fins with Impinging Flow," $J$. Heat Transf., pp. 570-577 (1996).

6. Lin, S.Y., "A Numerical Study on Thermal Analysis of Desktop Computers," Master Thesis, Department of Mechanical and Marine Engineering, National Taiwan Ocean University, Keelung, Taiwan, ROC (2002).

7. Maveety, J.G. and Jung, H.H., "Design of an Optimal Pin-Fin Heat Sink with Air Impingement Cooling," Int. Comm. Heat Mass Transf., Vol. 27, pp. 229-240 (2000).

8. Maveety, J.G. and Jung, H.H., "Heat Transfer from Square Pin-Fin Heat Sinks with Air Impingement Cooling," IEEE T. Compon. Pack. T., Vol. 25, pp. 459 -469 (2002).

9. "ESC Flow Solver and Modeling Theory," from http:// www.mayasim.com/expertise/papers/ 